\title{
ATUALIDADE DA PEDAGOGIA DO OPRIMIDO: CONSTRUINDO ESPERANÇA E MOBILIZANDO LUTAS EMANCIPATÓRIAS
}

\author{
HAMMES, Lúcio Jorge* \\ ZITKOSKI, Jaime José** \\ BOMBASSARO, Luiz Carlos****
}

\begin{abstract}
RESUMO
Este artigo tem como objetivo identificar as repercussões da Pedagogia do oprimido para a academia e para os movimentos sociais, de modo a contribuir com a formação humana e social em uma perspectiva crítica. Discute-se a atualidade do pensamento freiriano, em busca de compreender a sua força para mobilizar a esperança e organizar projetos e práticas que concretizem o ideário da Pedagogia do oprimido nas lutas da emancipação social. Trata-se de uma pesquisa qualitativa, que utilizou a abordagem da pesquisa documental e bibliográfica tendo por base o contexto da obra de Paulo Freire. Além disso, este texto analisa as repercussões da Pedagogia do oprimido para o contexto sociocultural contemporâneo. Os resultados apontam para a atualidade da obra, constituindo-se em base importante para os estudos universitários e para os movimentos sociais, contribuindo para a formação política e as lutas de libertação. Por isso, é uma das principais obras que vem sendo indicada como referência mundial na área da educação e das ciências humanas.
\end{abstract}

PALAVRAS-CHAVE: Pedagogia do Oprimido. Emancipação. Esperança. Pedagogia Crítica.

\footnotetext{
* Doutor em Educação. Professor dos cursos de licenciatura e do PPG em Educação da Universidade Federal do Pampa (UNIPAMPA). E-mail: luciojh@gmail.com

** Professor de Filosofia da Educação na FACED/UFRGS e no Pós Graduação em Educação da UFRGS. Email: jaime.jose@ufrgs.br

*** Professor de Filosofia na Faculdade de Educação da Universidade Federal do Rio Grande do Sul. E-mail: luiz.bombassaro@ufrgs.br 


\title{
TODAY'S PEDAGOGY OF THE OPPRESSED: BUILDING HOPE AND MOBILIZING EMANCIPATORY STRUGGLES
}

\author{
HAMMES, Lúcio Jorge* \\ ZITKOSKI, Jaime José** \\ BOMBASSARO, Luiz Carlos***
}

\begin{abstract}
This paper aims to identify the repercussions of the Pedagogy of the oppressed for the academy and social movements, in order to contribute to human and social education in a critical perspective. It discusses the currency of the Freirean thinking, seeking to understand its strength to mobilize hope and to organize projects and practices that concretize the ideology of Pedagogy of the oppressed in the struggles of social emancipation. It is a qualitative research that used the documentary and bibliographic research approach based on the context of Paulo Freire's work. In addition, this text analyzes the repercussions of the Pedagogy of the Oppressed to the contemporary sociocultural context. The results indicate the currency of the work, constituting an important basis for university studies and social movements, contributing to political education and liberation struggles. Therefore, it is one of the main works that has been indicated as a world reference in the area of education and the humanities.
\end{abstract}

KEYWORDS: Pedagogy of the Oppressed. Emancipation. Hope. Critical Pedagogy.

\footnotetext{
* Doctor of Education. Professor of Undergraduate and Graduate courses in Education at the Federal University of Pampa (UNIPAMPA).E-mail: luciojh@gmail.com

** Professor of Philosophy of Education at FACED / UFRGS and Post Graduation in Education at UFRGS.

E-mail: jaime.jose@ufrgs.br

*** Professor of Philosophy at the Faculty of Education of the Federal University of Rio Grande do Sul. E-mail: luiz.bombassaro@ufrgs.br 


\section{INTRODUÇÃO}

O presente artigo analisa a atualidade da Pedagogia do oprimido (FREIRE, 1993), que teve sua primeira edição em 1968 enquanto Paulo Freire estava vivendo no exílio, em Santiago do Chile. Destacamos a sua contribuição para fortalecer a esperança e para a elaboração de projetos e práticas junto aos movimentos emancipatórios. O horizonte de nossa análise reside na hipótese de que a Pedagogia do oprimido oferece chaves de leitura fecundas para interpretar a realidade do mundo atual e, igualmente, para organizarmos lutas emancipatórias no campo progressista e democrático.

Escrito em um contexto de perseguição política, Pedagogia do oprimido sistematiza experiências de educação popular desenvolvidas no Brasil, desde os anos de 1960, e no Chile, na organização das lutas por reforma agrária, onde Freire atuou intensamente, aprofundando a discussão dessas lutas libertárias no diálogo com autores que fundamentam a perspectiva da transformação social e da humanização. Dessa forma:

Mais uma vez os homens, desafiados pela dramaticidade da hora atual, se propõem a si mesmos como problema. Descobrem que pouco sabem de si mesmos como problema. Descobrem que pouco sabem de si, de seu "posto no cosmos", e se inquietam por saber mais. (FREIRE, 1993, p. 29).

O livro Pedagogia do oprimido era considerado perigoso e foi proibido no Brasil durante a Ditadura Militar e a sua circulação somente foi permitida a partir de 1974 em razão da sua força na mobilização das lutas por liberdade e democracia, pois a educação pode ajudar a empoderar os oprimidos. Além do Brasil, outros países da América Latina, além da África do Sul com o regime do apartheid e Tucson do Arizona nos Estados Unidos, também proibiram a sua publicaçãoi.

Passado meio século, Pedagogia do oprimido continua sendo um dos livros mais referenciados e reconhecidos internacionalmente. Conforme dados do projeto Open Syllabus ${ }^{\mathrm{ii}}$, Pedagogia do oprimido é o único livro brasileiro que entra no top 100 de universidades de língua inglesa que analisou as ementas dos cursos de universidades de língua inglesa, aparecendo em $99^{\circ}$ lugar no ranking geral, com 1.021 citações e, no campo de educação, a obra figura em segundo lugar, ficando apenas atrás do Teaching for quality learning in university: what the student does, de John Biggs (BIGGS; TANG, 2011).

Pedagogia do oprimido é um livro que inspira gerações. É obra básica nas bibliotecas da academia e nas associações populares. É traduzido para mais de 60 idiomas 
(GUIMARÃES, 2018). Na academia, é uma das obras mais mencionadas, sendo a terceira mais citada em trabalhos da área das ciências humanas (MONTESANTI, 2018), e provoca importantes transformações nos movimentos sociais, conforme o relato do educador Felipe Campelo, da Escola Popular do Movimento dos Trabalhadores Rurais Sem Terra (MST), onde é aplicado o método pedagógico do Paulo Freire: "Ele fez com que o processo de alfabetização fosse um processo de libertação, mais do que aprender a ler e a escrever, as pessoas aprendem um processo de leitura do mundo" (GUIMARÃES, 2018, n.p.).

$\mathrm{Na}$ perspectiva do reconhecimento internacional, destacamos o interesse de pesquisadores em conhecer o método de alfabetização de Paulo Freire e a sua proposta de formação da consciência crítica. Seu nome aparece em institutos acadêmicos de países como Finlândia, Inglaterra, Estados Unidos, África do Sul e Espanha. Além da obra de Paulo Freire, também os estudos sobre Freire têm impactado ações educativas e sociais no Brasil e no exterior. A sua obra é acolhida e traduzida para que seja acessível ao máximo de pessoas. Por exemplo, o livro de Vittoria (2011), que foi traduzido para o italiano e romeno, ressalta a atualidade e importância da obra de Paulo Freire no contexto atual.

A influência da obra de Paulo Freire fez com que ele recebesse o título de Patrono da Educação Brasileira (BRASIL, 2012). Seu ensinamento desacomoda e provoca reações aos leitores e participantes dos espaços organizados na perspectiva da educação popular que defendem a vida e a justiça social. Parte da realidade e da história e vai construindo o processo de aprendizagem. Provoca, também, reações de grupos radicais que ainda defendem privilégios de classe e o fim da educação com base nos ensinamentos de Paulo Freire (GUIMARÃES, 2018) $)^{\text {iii }}$. São controvérsias que hoje aparecem em movimentos e organizados em manifestações políticas, sociais, tendo por base uma produção intelectual que tenta evitar a força libertadora dessa obra.

A atualidade da Pedagogia do oprimido instiga à pesquisa. Nesse sentido, convém lançar a pergunta: Por que a leitura dessa obra renova a esperança e mobiliza coletivos de pessoas, facilitando a organização de projetos e práticas que ajudam nas lutas sociais, mesmo em situações precárias?

$\mathrm{O}$ artigo tem como objetivo identificar as repercussões da Pedagogia do oprimido para a academia e para os movimentos sociais, de forma a contribuir com a conscientização das pessoas. Por isso, este texto está organizado em dois pontos centrais. Além de uma introdução 
e das considerações finais, trazemos dados que ajudam a compreender a sua força para alimentar a esperança e contribuir com a emancipação social.

A metodologia deste estudo tem por base o contexto da produção da obra de Freire, com prioridade à Pedagogia do oprimido. A ênfase da análise centra-se na pesquisa qualitativa de cunho documental e bibliográfico, com o desafio de mostrar a sua influência no campo acadêmico e dos movimentos sociais.

\section{PARA ALIMENTAR A ESPERANÇA: A PEDAGOGIA DO OPRIMIDO CONTINUA ATUAL}

Paulo Freire está na origem da Educação Popular, como paradigma latino-americano que traz importantes contribuições para a pedagogia mundial. Ele foi um dos pioneiros na construção de propostas pedagógicas para impulsionar a articulação de lutas organizadas a partir de Movimentos Populares em direção à transformação das realidades sociais opressoras. Nesse contexto, que data dos anos de 1960, emergiu uma Pedagogia da libertação, para a qual o livro Pedagogia do oprimido é a referência central. Pela coragem e pela postura coerente de humildade e autocrítica, a proposta freiriana convergiu para um grande movimento de Práxis transformadora, que foi emergindo da realidade social latino-americana e passou a agrupar inúmeras lideranças, intelectuais e educadores de todo o mundo.

Freire continua atual na fundamentação teórica da Educação Popular pelo seu modo de pensar, de ler o mundo e de refletir sobre seu grande tema: a Educação, no sentido amplo da palavra. Desde os anos de 1960, quando Freire lançou suas primeiras obras mais sistemáticas, expressando sua proposta de educação, ele buscou rever a si mesmo, considerando as críticas que recebia de seus leitores e estudiosos. Por outro lado, sempre ficou atento ao dinamismo da realidade que nos desafia a reler constantemente o nosso mundo e rever nossas posições teóricas e práticas.

Em toda sua trajetória, como educador e teórico da educação, Freire buscou atualizar seu modo de pensar e refletir sobre os temas que abraçou como plano de trabalho. Portanto, mesmo tratando de problemáticas comuns em suas diferentes obras, Freire reelaborou suas ideias, recriando o raciocínio e a forma de abordar os problemas centrais por ele trabalhados e desafiou-nos com novas intuições sempre fecundas e originais. Ele próprio, ao discorrer sobre suas intuições, diz-nos: "As intuições têm muita força em mim, eu sou muito sensível às 
novas ideias, tanto que às vezes me concebo como adivinhador. Mas, o meu mérito é não ficar cego às intuições, mas submetê-las ao crivo crítico"’iv .

Nessa perspectiva, uma das intuições que Freire submeteu à análise e à reflexão crítica, ao longo de sua trajetória de educador e filósofo da educação, é a problemática da libertação das pessoas concretamente em suas vidas desumanizadas pela opressão e pela dominação social. Essa foi a luta travada por Freire e sua proposta pedagógica traduz, de forma integral, as preocupações que perpassam de início ao fim sua atuação prática de educador e de intelectual.

O desafio maior que Freire lançou a si mesmo e para quem compartilha do mesmo sonho e da mesma utopia é a humanização do mundo por meio da ação cultural libertadora. ${ }^{v}$ Esse desafio, sem sombras de dúvida, continua hoje mais atual do que há vinte ou trinta anos e requer de nós, seres humanos sujeitos da história, um compromisso ético e político claramente definido em favor da transformação da realidade. O mundo real que nos cerca é intrinsecamente dialético porque, efetivando-se historicamente, nos constitui e, ao mesmo tempo, é constituído por nós como sujeitos da práxis social. Frente aos problemas que a realidade atual nos apresenta, precisamos, portanto, impulsionar novos momentos de ação para atingir outros níveis de humanização do mundo, da sociedade e da cultura.

A humanização do mundo atual exige que repensemos muitos aspectos da vida em sociedade. Dentre seus vários aspectos, destacamos a necessidade de repensarmos a educação que praticamos, as relações humanas na sua cotidianidade prática da economia e da vida privada, as posturas políticas e as relações sociais delas resultantes, a produção do conhecimento científico-técnico que está na base da reprodução dos sistemas hegemônicos da sociedade.

Paulo Freire, em seus últimos escritos, principalmente na Pedagogia da esperança (1994) e Pedagogia da autonomia (1996), deu importantes passos nesse sentido, reelaborando seu próprio pensamento à luz dos novos contextos socioculturais inaugurados nos anos de 1990. Dessa forma, não podemos ler Paulo Freire hoje sem a visão do capitalismo globalizado e/ou sem levar em conta sua crítica ao neoliberalismo.

O que nos chama atenção em suas últimas obras é a compreensão de que o capitalismo se transformou e já não segue a mesma lógica dos anos de 1960, 1970 ou 1980. Transformaram-se as relações sociais que tinham como base o taylorismo-fordismo, o capital 
financeiro tornou-se dominante a partir das novas tecnologias e, principalmente, por meio do domínio do conhecimento técnico. Igualmente, o capitalismo atual transforma os imaginários sociais, em especial aquele das classes populares pela força arrebatadora da indústria cultural de massas. Dessa forma, estamos diante de uma nova forma de dominação social e política, arquitetada a partir da força da imagem que regulamenta e controla a vida quotidiana das massas populacionais, por intermédio do poder da mídia.

Esse poder ideológico da mídia é usado de modo estratégico pelas elites dominantes, mundialmente, na busca de reciclar sua forma de dominação a partir do projeto da globalização econômica ancorada no livre mercado e no consumismo como fim último da ordem social.

A capacidade de penumbrar a realidade, de nos 'miopizar', de nos ensurdecer que tem a ideologia faz, por exemplo, a muitos de nós, aceitar docilmente o discurso cinicamente fatalista neo-liberal que proclama ser o desemprego no mundo uma desgraça de fim de século. Ou que os sonhos morreram e o válido hoje é o 'pragmatismo'. (FREIRE, 1996, p. 142).

Diante desse contexto, Freire deixou-nos muitas intuições para repensar o mundo atual à luz do projeto de reconstrução da ação crítica libertadora. O ponto de partida dessa tarefa reside no fato de que a exclusão e a opressão social não desapareceram. Muito pelo contrário, ampliaram seus quadros acrescentando a novos contingentes populacionais as consequências de sua lógica perversa. Portanto, há de reconstruir-se o projeto social emancipador e, por essa razão, a ideia de utopia e esperança no futuro histórico da humanidade que aparece em Freire como contracultura e/ou contradiscurso frente à ideologia dominante dos anos de 1990.

Não há mudança sem sonho, como não há sonho sem esperança. Por isso, venho insistindo [...] que não há utopia verdadeira fora da tensão entre a denúncia de um presente tornando-se cada vez mais intolerável e o anúncio de um futuro a ser criado [...]. A utopia implica essa denúncia e esse anúncio. (FREIRE, 1994, p. 91).

A afirmação histórica do ser humano como ser em busca de liberdade e esperançoso é a base para construir a visão ética e política indispensável ao projeto de transformação social e/ou à reinvenção do paradigma emancipatório de sociedade. Nesse sentido, Freire acentua o caráter fundante da denúncia e do anúncio para as práticas sociais que se orientam para a emancipação. São essas práticas que criam as condições iniciais para a efetivação da transformação social. 
Freire oferece propostas antropológicas fecundas, que podem nos inspirar no futuro próximo em novos processos práticos de transformação e humanização da sociedade. Assim, o conceito de dialogicidade é o pano de fundo de uma visão antropológica fecunda, que produz um pensamento radicalmente humanista e libertador. Ao colocar o diálogo como condição primeira da libertação dos oprimidos, Freire fundamenta o projeto de transformação social em bases renovadas que convergem para a humanização sociocultural da humanidade em seu todo.

A dialogicidade é a prática do diálogo verdadeiro, que mantém viva a dialeticidade entre ação e reflexão. Essa prática dialógica e dialética da nossa vida concreta é uma exigência existencial do ser humano, pois se constitui na própria vocação de nossa espécie radicalmente aberta ao mundo e, por isso mesmo, é histórica, incompleta e sedenta de humanização. É pelo diálogo que implica uma atitude de vida, que os homens e as mulheres constroem um mundo humano, de modo a refazer o que já existe e projetar um futuro que está por realizar-se.

A existência, porque humana, não pode ser muda, nem tampouco pode nutrir-se de falsas palavras, mas de palavras verdadeiras, com que os homens transformam o mundo. Existir humanamente, é pronunciar o mundo, é modificá-lo. O mundo pronunciado, por sua vez, se volta problematizado aos sujeitos pronunciantes, a exigir deles novo pronunciar. (FREIRE, 1993, p. 78).

Nesses termos, o fundamento central da proposta antropológica freiriana é o diálogo. É na palavra pronunciada, que revela o mundo, que os homens se fazem ao fazer e refazer o próprio mundo (FIORI apud FREIRE, 1993). O diálogo é, então, esse encontro dos homens, mediatizados pelo mundo (FIORI apud FREIRE, 1993). E, consequentemente, a cada ser humano impõe-se o desafio do aprender a dizer a sua palavra, como exigência fundamental de sua humanização. É a partir dessa pronúncia singular que nós nos tornamos sujeitos históricos capazes de construir intersubjetivamente uma sociedade em comunhão de objetivos e vivências.

O diálogo fenominiza e historiciza a essencial intersubjetividade humana; ele é relacional e, nele, ninguém tem iniciativa absoluta. Os dialogantes 'admiram' um mesmo mundo; afastam-se dele e com ele coincidem; nele põem-se e opõem-se [...]. O diálogo não é produto histórico, é a própria história (FIORI apud FREIRE, 1993, p. 16). 
A partir do conceito de dialogicidade, o pensamento freiriano conquista uma originalidade e fecundidade exemplares em termos de visão antropológica coerente para analisar a história e a sociedade contemporâneas. As concepções freirianas de ser humano e sociedade, bem como sua visão de história como processo de humanização do mundo, inspiram uma racionalidade original e originária como fundamento de sua proposta antropológica, política, epistemológica e ética.

É importante insistir em que, ao falar do 'ser mais' ou da humanização como vacação ontológica do ser humano, não estou caindo em nenhuma posição fundamentalista [...]. Daí que insista também em que esta 'vocação', em lugar de ser algo a priori da história é, pelo contrário, algo que se vem constituindo na história. (FREIRE, 1994, p. 99).

O fundamento de uma pedagogia dialógica em Freire (1994) emerge da própria natureza do ser humano em sua autoconstrução na história, que mostra uma essencial abertura diante do mundo e dos outros, porque é um ser inconcluso, inacabado, incompleto e existencialmente insatisfeito com o que já é. Essa abertura ao novo, às possibilidades que estão por realizar-se, é o que impulsiona a nós, seres humanos, para o ser mais. É uma característica própria da nossa espécie que Freire chama de vocação ontológica para a humanização, ressalvando que tal vocação não deve ser entendida como algo inato e/ou um $a$ priori.

A natureza humana vai, por conseguinte, se processando na história a partir da luta pela liberdade e/ou afirmação livre das pessoas. E essa luta tem como impulso a racionalidade dialógica que, da mesma forma, não é um a priori, mas uma condição existencial da própria humanização, que se processa historicamente em um mundo concreto e exige a superação das situações limites que nos condicionam e/ou oprimem.

Então, ao concebermos uma Pedagogia do diálogo em Freire, compreendemos seu conceito de dialogicidade, ser humano, visão de história, sociedade, política e educação, como proposta de humanização do mundo e recriação da cultura em suas diferentes formas de realizar o potencial o ser mais intrínseco à vida humana. Essa proposta implica entender o ser humano não apenas como razão, estrutura lógica, consciência. A concepção antropológica de Freire converge para uma visão integral da existência humana, ao valorizar, de forma equilibrada, todas as dimensões de nossa vida: corpo, mente, coração, sentimento, emoções, sentido, intelecto, razão, consciência, entre outras. Como nos diz Freire (1995): 
A consciência do mundo, que implica a consciência de mim no mundo, com ele e com os outros, que implica também a nossa capacidade de perceber o mundo, de compreendê-lo, não se reduz a uma experiência racionalista. É como uma totalidade - razão, sentimentos, emoções, desejos - que meu corpo consciente do mundo e de mim capta o mundo a que se intenciona. (FREIRE, 1995, p. 75).

Nesse sentido, Freire define o conceito de corpo consciente como base para superar a histórica dicotomia entre corpo-espírito; sentidos-razão, que predominou na filosofia ocidental e continua hoje na raiz dos processos culturais opressores e alienantes da existência humana. A denúncia de Freire à visão antropológica tradicional parte do fato de que esta:

Sugere uma dicotomia inexistente homens-mundo. Homens simplesmente no mundo e não com o mundo e como os outros. Homens espectadores e não recriadores do mundo. Concebe a sua consciência como algo espacializado neles e não aos homens como ‘corpos conscientes'. (FREIRE, 1993, p. 63).

Ao contrário do que essa visão objetivista define, Freire entende que o ser humano se constitui dialeticamente e, por isso mesmo, dialogicamente com o mundo. A vida humana é abertura ativa ao mundo porque a essência da consciência humana é atividade, intencionalidade, relação com os outros e com as diferentes realidades existentes no mundo. E, portanto, somente na comunicação tem sentido a vida humana, por que é a partir da relação dialógica de quem se comunica que é possível o verdadeiro "con-viver", ser com os outros e humanizar-se em comunhão. Ou seja, o diálogo que alimenta a comunicação é a alavanca do verdadeiro processo educativo do ser humano.

Ao contrário da 'bancária', a educação problematizadora, respondendo à essência do ser da consciência, que é sua intencionalidade, nega os comunicados e existência a comunicação. Identifica-se com o próprio da consciência que é sempre ser consciência de, não apenas quando se intenciona a objetos, mas também quando se volta sobre si mesma. (FREIRE, 1993, p. 67).

A partir de uma visão antropológica inovadora e fecunda em Freire, podemos repensar as tramas e as potencialidades do existir humano no mundo sociocultural da atualidade, de forma a apontar para os seguintes desdobramentos pedagógicos:

1) No Legado de Freire, de modo mais sistemático na Pedagogia do oprimido, encontra-se uma análise crítica sistematizada do mundo da opressão em seus processos culturais, que hoje desumanizam milhões de pessoas no mundo. Contudo, além da crítica, Freire constrói 
novas bases antropológicas para desenvolver novos processos históricos rumo à elaboração de uma cultura dialógica, libertadora e emancipatória.

2) A dialogicidade, ação dialógica ou ação cultural para a liberdade é concebida por Freire como um caminho de reconstrução da vida em sociedade e, portanto, um projeto maior, que se articula a partir de uma visão de sociedade igualitária, concepção de vida humana dialógica e dialética e uma proposta de educação radicalmente libertadora que, no conjunto, se articulam a partir da racionalidade dialógica. É uma proposta pedagógica que busca construir a existência humana de modo crítico e criativo frente aos mecanismos socioculturais que nos condicionam, atrofiam e objetualizam/reificam no contexto de hoje.

3) A mobilização da esperança: Freire é esperançoso diante do desafio de construirmos uma sociedade mais igualitária, justa e solidária. No entanto, para que esse sonho ou utopia de sociedade se torne realidade concreta na história da humanidade, ele defende a afirmação de uma nova cultura, como busca de sentido para o nosso viver e existir no mundo. Essa cultura brota do impulso de liberdade dos oprimidos e segue uma lógica anárquica frente aos sistemas vigentes, porque se orienta por uma racionalidade distinta. A racionalidade preconizada aqui define-se pelo seu potencial dialógico, amoroso e humanista, como base para elaborar uma cultura biófila, crítica e essencialmente libertadora.

4) A pedagogia dialógica libertadora como obra coletiva, que não é apenas sonho, utopia e/ou idealização, mas um processo que já está sendo construído por meio dos diferentes movimentos que produzem novas experiências de vida em sociedade. A história de organização dos setores marginalizados e/ou excluídos da sociedade em países latinoamericanos, por exemplo, demonstra que a vida humana revela sempre novas potencialidades diante dos condicionantes sócio-históricos que a atrofiam. Dessa maneira, a Pedagogia do oprimido não é um livro apenas e nem uma obra só de Paulo Freire, mas um projeto coletivo sonhado por milhões em todo o mundo. Uma obra que inspira e mobiliza projetos sociais e coletivos engajados em lutas emancipatórias. É, portanto, uma pedagogia em construção que está em curso na sociedade atual. 


\section{PROJETOS E PRÁTICAS QUE CONCRETIZAM O IDEÁRIO DA PEDAGOGIA DO OPRIMIDO: A EDUCAÇÃO EM MOVIMENTOS EMANCIPATÓRIOS}

A Pedagogia do oprimido, ao transformar-se em obra coletiva e efetivar-se como história de organização das lutas emancipatórias, objetiva-se em diferentes projetos e práticas sociais. A seguir, buscamos delinear alguns desdobramentos centrais desse processo em curso na América Latina, principalmente no Brasil, de forma mais diretamente relacionada ao nosso contexto cultural.

\section{a) Educação Popular como um paradigma pedagógico inovador}

A Educação Popular desponta na América Latina a partir da década de 1960 como um paradigma pedagógico original no contexto da educação do século XX. Entre as diferentes características que constituem a Educação Popular como contribuição latino-americana, destacam-se os seguintes aspectos:

Que toda educação é política: Desde seus primeiros escritos, Freire (1993) insiste que não há educação neutra política e eticamente. Toda educação é uma prática social e, dessa forma, ou está comprometida com a transformação dos sistemas opressores e, portanto, em busca da libertação, ou está reproduzindo a lógica da dominação social.

A educação não é uma prática social que ocorre só na escola ou no sistema formal de ensino. De acordo com a perspectiva da Educação Popular, educação é sinônimo de humanização. Assim, não ocorre educação de fato quando na prática não se busca desenvolver o "ser mais" de cada pessoa envolvida no processo, inclusive dos educadores. Nesse sentido, a Educação Popular tem revelado desde a origem seu compromisso ético-político com os oprimidos, com as vítimas de todos os processos de opressão social. Segundo Freire (1993), nosso trabalho educativo deve estar explicitamente voltado para: "Os esfarrapados do mundo e aos que nele se descobrem e, assim descobrindo-se, com eles sofrem, mas, sobretudo, com eles lutam" (FREIRE, 1993, p. 17).

A Educação Popular na América Latina está, por conseguinte, historicamente articulada às lutas populares e aos Movimentos Sociais Progressistas, que se identificam diante do desafio de construir um novo projeto de sociedade onde não seja impossível sonhar com uma vida digna para todos. Nessa perspectiva, é que a Educação Popular inaugura uma nova pedagogia no século XX. É uma pedagogia comprometida com a libertação dos seres humanos em todas as suas dimensões: erótica, pedagógica, econômica, política e ética. 
Libertação esta que aposta em uma vida social em que não poderá existir mais nem opressores e nem oprimidos, mas seres humanos em busca de sua humanidade plena.

\section{b) Educação popular e movimentos sociais}

No período de mais de cinco décadas de experiências inovadoras com o propósito de organizar e qualificar os Movimentos Sociais, a Educação Popular tem acumulado referenciais teóricos e metodologias de trabalho político-pedagógicos que revelam a riqueza e a sabedoria das classes populares em diálogo com saberes acadêmicos.

A partir do desafio de organizar-se para ter mais poder de luta por direitos sociais e na busca de construir um novo projeto de sociedade, tem se destacado, por exemplo, em plena época da Ditadura Militar no Brasil, o Método Ver - Julgar - Agir. É um método que esteve muito presente nas Comunidades Eclesiais de Base (CEBs) e, hoje, ainda é fecundo nas pastorais sociais. Outra experiência metodológica fecunda da Educação Popular está relacionada à Pesquisa Participante, em que autores como Carlos Brandão, Paulo Freire, Fals Borda, entre outros, nos trazem propostas concretas de uma metodologia que busca a síntese do saber popular com os saberes acadêmicos.

O desafio maior é organizar as classes populares para articular as diferentes iniciativas dos Movimentos sociais em seus acúmulos históricos na busca de construir uma rede ou movimento social de maior amplitude e abrangência entre as classes populares. Nessa direção, a proposta de Freire é categórica ao colocar a importância do sonho e da esperança na construção de uma pedagogia da luta política.

O sonho pela humanização, cuja concretização é sempre processo, e sempre devir, passa pela ruptura das amarras reais, concretas, de ordem econômica, política, social, ideológica, etc. que nos estão condenando à desumanização. O sonho é assim uma exigência, ou uma condição que se vem fazendo permanente na história que fazemos e que nos faz e re-faz. (FREIRE, 1994, p. 99).

\section{c) Um referencial teórico-metodológico fecundo}

O referencial teórico da Educação Popular articula o pensamento dialético, buscando construir uma pedagogia da práxis, tensionando sempre a relação teoria-prática ${ }^{\mathrm{vi}}$ com o pensamento fenomenológico de vertente existencialista. Nessa perspectiva, é que emerge a pesquisa participante como um referencial teórico-metodológico inovador. A realidade social, cultural e política dos povos latino-americanos é o ponto de partida da Educação Popular na 
busca de potencializar a organização dos Movimentos Sociais progressistas. Um exemplo prático desse caminho metodológico é a pesquisa dos Temas Geradores, que está bem delineada por Freire no terceiro capítulo de sua Pedagogia do oprimido. Outra construção fecunda é a pesquisa sócio-antropológica nos projetos da Escola Cidadã, que desponta nos anos de 1990 com as administrações populares nos municípios brasileiros.

$\mathrm{O}$ aspecto inédito dessas propostas metodológicas está na coerência em propor um caminho interdisciplinar na construção de saberes necessários para a libertação e humanização dos oprimidos e praticar o diálogo entre os diferentes núcleos/ethos culturais na perspectiva da elaboração de uma ciência biófila, que considere a vida um valor básico. Educação, nessa perspectiva, não significa apenas escola, saber formal, instrução, mas formação de um novo ser humano que, ao mesmo tempo, testemunha e vivencia novas práticas sociais, humanistas e libertadoras e luta em todos os espaços de vida em sociedade para construir uma cultura crítico-humanizadora - de afirmação de uma nova humanidade. Eis o propósito ético-político da Educação Popular como nova pedagogia para a América Latina.

\section{d) $O$ empoderamento das classes populares}

Nas quase cinco décadas de práticas de Educação Popular e organização das lutas e afirmação de conquistas pelos movimentos populares, ocorreu um acúmulo de experiências inovadoras na forma de construir o poder das classes populares. Mesmo a partir das experiências das administrações populares no Brasil, pelo menos no âmbito das administrações municipais, foram sendo construídas relações mais democráticas entre Estado e Sociedade Civil e surgiram alternativas criativas na perspectiva da democracia participativa e participação popular, tais como: Orçamento participativo, Economia Solidária, Fórum Social Mundial, entre outras.

Essas iniciativas mostram para a história da humanidade que é possível sim articular as experiências de organização local com movimentos de âmbito nacional e internacional. Acima de tudo, as várias edições do Fórum Social Mundial organizadas a partir de Porto Alegre convergiram para o desafio de organizar lutas populares globalmente, na busca de resistência e de construção de alternativas ao modelo da política neoliberal, profundamente excludente, opressora e destrutiva de todo nosso planeta azul - nossa única casa comum.

Todas as conquistas alcançadas até hoje nos mostram que nada vem ao acaso e que a história humana é permeada de contradições e incompletudes. As lutas sociais por dignidade, 
direitos dos povos, de suas culturas, de uma vida digna a partir da natureza preservada para as futuras gerações constituem uma luta que diz respeito a todos como latino-americanos. Por um lado, essa luta está em curso e, até hoje, temos pouco a comemorar de conquistas reais. Por outro lado, enquanto existir luta e sonho coletivo dos povos oprimidos de nossa América Latina, a história estará viva e a esperança haverá de triunfar apesar de todo sofrimento e destruição de vidas, que possam ter sido impostos pelos conquistadores, que pensavam e ainda se consideram donos do mundo.

\section{e) Educação popular e escola pública popular}

A partir das experiências das administrações populares de 1989 e, principalmente, com o desafio pessoal de Paulo Freire como Secretário de Educação na cidade de São Paulo no governo Luiza Erundina, teve início no Brasil um movimento para construir alternativas pedagógicas no interior das redes públicas de escolas a partir dos princípios e das propostas da Educação Popular. O Movimento que passou a se chamar de Escola Cidadã teve origem em São Paulo com a administração de Paulo Freire. Se são as classes populares que frequentam majoritariamente as escolas públicas, por que estas escolas funcionam na lógica das elites? Elas não poderiam ser reorganizadas para se aproximarem da lógica cultural e dos interesses das classes populares?

Eis a origem do debate para a busca de reinvenção da escola pública a partir das experiências e do referencial teórico-metodológico da Educação Popular. Se esse desafio foi concretizado, ainda não se pode responder com toda clareza, mas o movimento está em curso e já acumulou muitas experiências positivas. Podemos citar algumas cidades que buscaram concretizar o projeto Escola Cidadã: São Paulo, Porto Alegre, Caxias do Sul, Alvorada, Chapecó, Cuiabá, Novo Hamburgo, entre outras. Sobre a experiência de Porto Alegre, há diferentes registros e livros organizados que analisam o êxito obtido, dentre os quais destacamos Azevedo et al. (2000) e Silva, Azevedo e Santos (1997). Uma das publicações mais expressivas desse movimento é o livro organizado por Carlos Rodrigues Brandão (2002), intitulado A Educação popular na Escola Cidadã. 


\section{f) Projetos das Cidades Educadoras}

A concepção de Cidade Educadora está diretamente vinculada à participação popular, pois, a partir desta, é possível delinear a formação de uma cidadania emancipatória na busca da construção de uma sociedade fundada na democracia real e na justiça social.

O conceito "Cidade Educadora" assume como um dos seus princípios básicos que o poder público municipal e a sociedade civil organizada, de forma articulada, precisam exercer sua função educadora na construção de uma nova cultura política, que se fundamenta na solidariedade entre pessoas, grupos sociais e instituições para enfrentar a lógica individualista e excludente do neoliberalismo em curso.

Cidade Educadora não é, pois, uma ação educadora qualquer, mas um projeto educativo vinculado aos processos democráticos e participativos, que estão emergindo no Brasil e na América Latina a partir dos movimentos sociais progressistas. É um projeto educativo que assimila, mas supera os princípios e os conceitos da educação escolar. Mais que isso, a Cidade Educadora educa a própria escola e é educada por ela, que passa a assumir, nessa perspectiva, um papel mais amplo na superação da violência e da exclusão social.

Não basta a educação escolar trabalhar em prol da formação de uma cultura cidadã, embora isso seja importante como articulação da vida social na comunidade. Como agentes sociais e políticos, comprometidos com um projeto social democrático e justo, precisamos ampliar a abrangência de nossas ações rumo à cidadania emancipatória. A educação concebida em um sentido mais amplo, para além dos marcos formais da escolarização, precisa estar vinculada aos objetivos estratégicos de um projeto social que busque, não apenas a inclusão nessa sociedade desigual, mas a construção de uma nova sociedade, fundada na igualdade política, econômica e social.

Nessa perspectiva, o projeto das Cidades Educadoras articula-se ao movimento da Escola Cidadã, mas quer ir além da escola. É um desafio mais articulado e interdisciplinar entre as diferentes áreas de atuação do poder local e articulação da participação popular no âmbito municipal. Segundo Gadotti, Padilha e Cabezudo (2004), o papel das políticas públicas no contexto do movimento Cidades Educadoras é contribuir para criar as condições que viabilizem a cidadania, por meio da socialização das informações, da discussão das prioridades para os diferentes setores sociais, da transparência dos recursos públicos, gerando, 
assim, uma nova mentalidade e uma nova cultura em relação ao caráter público do espaço da cidade.

\section{g) Educação popular e economia solidária}

As iniciativas da Economia Solidária que buscam construir novas formas de organização do mundo do trabalho e afirmar o compromisso coletivo com o projeto de sociedade das classes populares são esperança de libertação e de construção de uma cidadania emancipatória.

O trabalho coletivo, organizado a partir dos movimentos sociais, tais como os assentamentos do MST e as iniciativas do MTD (Movimento dos Trabalhadores desempregados), além da reciclagem de lixo no meio urbano a partir de Associações populares, é um horizonte que desponta de modo mais forte nos anos de 1990. São experiências que têm sua identidade no desafio de organização dos movimentos sociais populares e na busca de alternativas diante da lógica do capital, que é cada vez mais excludente e predatória diante das questões sociais e do meio ambiente.

A economia solidária autêntica assume o desafio de pensar novos fundamentos para a questão do trabalho e para a sustentação da vida. Esse desafio remete-nos a trabalhar não só a produção, mas o próprio consumo. E, como desafio maior, precisamos repensar o próprio projeto de vida, retomando talvez a sabedoria popular dos povos indígenas, que dialoga com a natureza e o universo de forma mais harmônica e integrada com todas as dimensões de nossa existência: a política, cultural, social, religiosa e econômica.

\section{h) Educação Popular e Orçamento Participativo}

A Educação Popular também reflete sobre os novos contextos do poder político, não somente aqueles relacionados à conquista do poder pelas classes populares, mas especialmente aqueles associados à necessária reinvenção do poder. O Orçamento Participativo é uma experiência que despontou junto às administrações populares nos anos de 1990. Contudo, para além da prática do Orçamento Participativo, novas formas de participação política são colocadas como desafio para o maior empoderamento das classes populares. Nesse sentido, coloca-se a questão: como articular as experiências locais com o poder regional, nacional e internacional? Como os movimentos sociais populares poderão se 
fortalecer na luta por uma nova sociedade na América Latina no atual contexto das políticas neoliberais?

Não há receitas prontas para fazer história ou organizar a luta popular. No entanto, uma questão fundamental está colocada para as classes populares, a saber: construir a sabedoria política na luta a partir da união dos diferentes para lutar contra os antagônicos (FREIRE, 1994). Essa articulação entre os movimentos sociais exige diálogo, humildade e uma educação da esperança. Não podemos, pois, cair no imediatismo e nem reproduzir a lógica da competição ou da cultura anti-solidária. Tudo isso nos enfraquece na luta e nos deixa reféns da mesma lógica que hoje sofremos - a dominação de uns sobre os demais.

\section{CONSIDERAÇÕES FINAIS}

Após 50 anos do lançamento da obra Pedagogia do oprimido, as pesquisas revelam que essa obra continua muito atual e é fundamental para a academia, o movimento social e a educação popular. É destaque nas referências dos cursos universitários, como também serve de inspiração aos movimentos progressistas. Ela ajuda cultivar a esperança e a elaborar propostas práticas de emancipação popular como destacamos ao falar sobre os projetos sociais.

O autor da Pedagogia do oprimido mostra-se coerente ética e politicamente no compromisso com a libertação dos oprimidos. Apresenta uma base teórica consistente sobre a temática analisada e desenvolve suas ideias com base na experiência da formação política e da construção de alternativas especialmente para a Educação Popular no Brasil e no Chile.

As análises revelam a grande abertura e a interconexão de seu pensamento com os temas centrais da contemporaneidade. E, dado que a área da educação é interdisciplinar por natureza, Freire inspira-nos a pensar criticamente várias temáticas, tais como: Educação de Jovens e Adultos, Educação Popular, Meio Ambiente, Formação de professores, Gestão democrática, Políticas públicas, Didática e métodos alternativos, Direitos Humanos, Movimentos Sociais, Educação ambiental, entre outros.

Pretendemos mostrar aqui que as concepções básicas contidas no livro Pedagogia do oprimido ajudam a repensar as tramas e as potencialidades do existir humano no mundo, destacando a capacidade de criticar a opressão e elaborar bases antropológicas para o diálogo na luta por libertação e emancipação. No diálogo, é possível formar a humanidade crítica e criativa frente aos mecanismos que condicionam, atrofiam e objetualizam as pessoas. $\mathrm{O}$ 
processo educativo dialógico mobiliza a esperança que se constitui a base para a elaboração da cultura biófila, crítica e libertadora.

A pedagogia do diálogo presente na Pedagogia do oprimido não é apenas um "sonho que se sonha só", mas constitui um processo já em curso nos movimentos que produzem novas experiências de vida. Tal pedagogia ajuda na organização dos oprimidos, demonstrando que a vida humana revela sempre novas potencialidades diante dos condicionantes sóciohistóricos que a atrofiam. Assim, o pensamento freireano inspira e mobiliza projetos sociais e coletivos engajados em lutas emancipatórias.

Para finalizar nossa reflexão, destacamos que os ensinamentos de Paulo Freire na Pedagogia do oprimido ajudam a unir os diferentes oprimidos na luta contra os antagônicos pela libertação de si mesmos e dos próprios opressores. Esse é o grande objetivo de Freire em sua Pedagogia da libertação. Pois, com uma perspectiva dialógica, a partir dos movimentos sociais, é possível superar a lógica da competição destrutiva (antissocial), que ainda hoje ameaça a dignidade humana e o próprio futuro da humanidade. 


\section{REFERÊNCIAS}

AZEVEDO, José Clóvis et al. Utopia e democracia na Educação Cidadã. Porto Alegre: Editora UFRGS; Secretaria Municipal de Educação, 2000.

BIGGS, John Burville; TANG, Catherine So-Kum. Teaching for quality learning at university. 4. ed. Maidenhead: Open University Press, 2011. E-book.

BRANDÃO, Carlos R. A Educação popular na escola cidadã. Petrópolis: Vozes, 2002.

BRASIL. Lei No 12.612, de 13 de abril de 2012. Declara o educador Paulo Freire Patrono da Educação Brasileira. Brasília, 2012. Disponível em: http://www.planalto.gov.br/ccivil_03/_Ato2011-2014/2012/Lei/L12612.htm. Acesso em: 10 set. 2018.

FREIRE, Paulo. Pedagogia da autonomia. São Paulo: Paz e Terra, 1996.

Pedagogia da esperança. São Paulo: Paz e Terra, 1994.

. Pedagogia da indignação. São Paulo: UNESP, 1995.

. Pedagogia do oprimido. São Paulo: Paz e Terra, 1993.

GADOTTI, Moacir; PADILHA, Paulo; CABEZUDO, Alicia. (Orgs.). Cidade Educadora: princípios e experiências. São Paulo: Cortez, 2004.

GUIMARÃES, Juca. Paulo Freire, 97 anos: o legado do brasileiro que ensinou o mundo a ler a si mesmo. Brasil de Fato, São Paulo, 19 set. 2018. Disponível em: https://www.brasildefato.com.br/2018/09/19/paulo-freire-97-anos-o-legado-do-brasileiro-queensinou-o-mundo-a-ler-a-si-mesmo/. Acesso em: 10 set. 2018.

MONTESANTI, Beatriz. Paulo Freire é o terceiro pensador mais citado em trabalhos pelo mundo. Nexo, 6 jun. 2018.2 Disponível em: https://www.nexojornal.com.br/expresso/2016/06/04/Paulo-Freire-\%C3\%A9-o-terceiropensador-mais-citado-em-trabalhos-pelo-mundo. Acesso em: 10 set. 2018.

SILVA, Luiz Heron da; AZEVEDO, José Clóvis; SANTOS, Edmilson S. dos. Identidade Social e a Construção do Conhecimento. Porto Alegre: Prefeitura Municipal, 1997.

VITTORIA, Paolo. Narrando Paulo Freire: por uma pedagogia do diálogo: Rio de Janeiro: UFRJ, 2011. 
${ }^{\text {i }}$ Estudos mostram que o livro da Pedagogia do oprimido foi proibido em regiões autoritárias para evitar o acesso à leitura crítica, que contribuía para a libertação das pessoas oprimidas. Chama atenção que, em 2010, um grupo de parlamentares republicanos aprovaram uma lei proibindo materiais que promovessem a derrubada dos Estados Unidos. Confira dados disponíveis em: https://brazilian.report/opinion/2018/08/24/paulo-freirepedagogy-opressed/. Acesso em: 10 set. 2018.

ii The Open Syllabus Project. Disponível em: http://explorer.opensyllabusproject.org/text/1229450. Acesso em: 20 set. 2018. Foram analisados programas de estudos de universidades dos Estados Unidos, Reino Unido, Austrália e Nova Zelândia para identificar quais são os livros mais solicitados por elas em suas ementas.

iii A partir de 2013, o Movimento Brasil Livre (MBL) lidera os manifestantes vestidos de verde e amarelo, os quais ostentavam faixas pedindo fim à "doutrinação marxista" e um basta à pedagogia de Freire nas escolas. Promovem o ódio contra o educador que culminou em um abaixo-assinado online pela revogação da Lei $\mathrm{N}^{\circ}$ 12.612, de 13 de abril de 2012, que concedeu o título a Freire (BRASIL, 2012).

${ }^{\text {iv }}$ É um depoimento vivo pronunciado por Freire em Palestra realizada no Simpósio Paulo Freire nos dias 4, 5 e 6 de setembro de 1996 em Vitória/ES. Na oportunidade, um dos autores deste artigo (Jaime Zitkoski) esteve presente, tendo a felicidade de participar e sentir de perto a efervescência das ideias freirianas, hoje se processando em diferentes realidades da América Latina e outros continentes.

${ }^{\vee}$ Ver, por exemplo, o último capítulo da Pedagogia do oprimido, que tematiza o processo dialético de superação da cultura opressora por uma nova cultura humanista e libertadora capaz de, a partir dos oprimidos, libertar a todos, tanto aos opressores, quanto aos oprimidos.

${ }^{\text {vi }}$ Ver, por exemplo, o início do $3^{\circ}$ capítulo da Pedagogia do oprimido de Paulo Freire. 